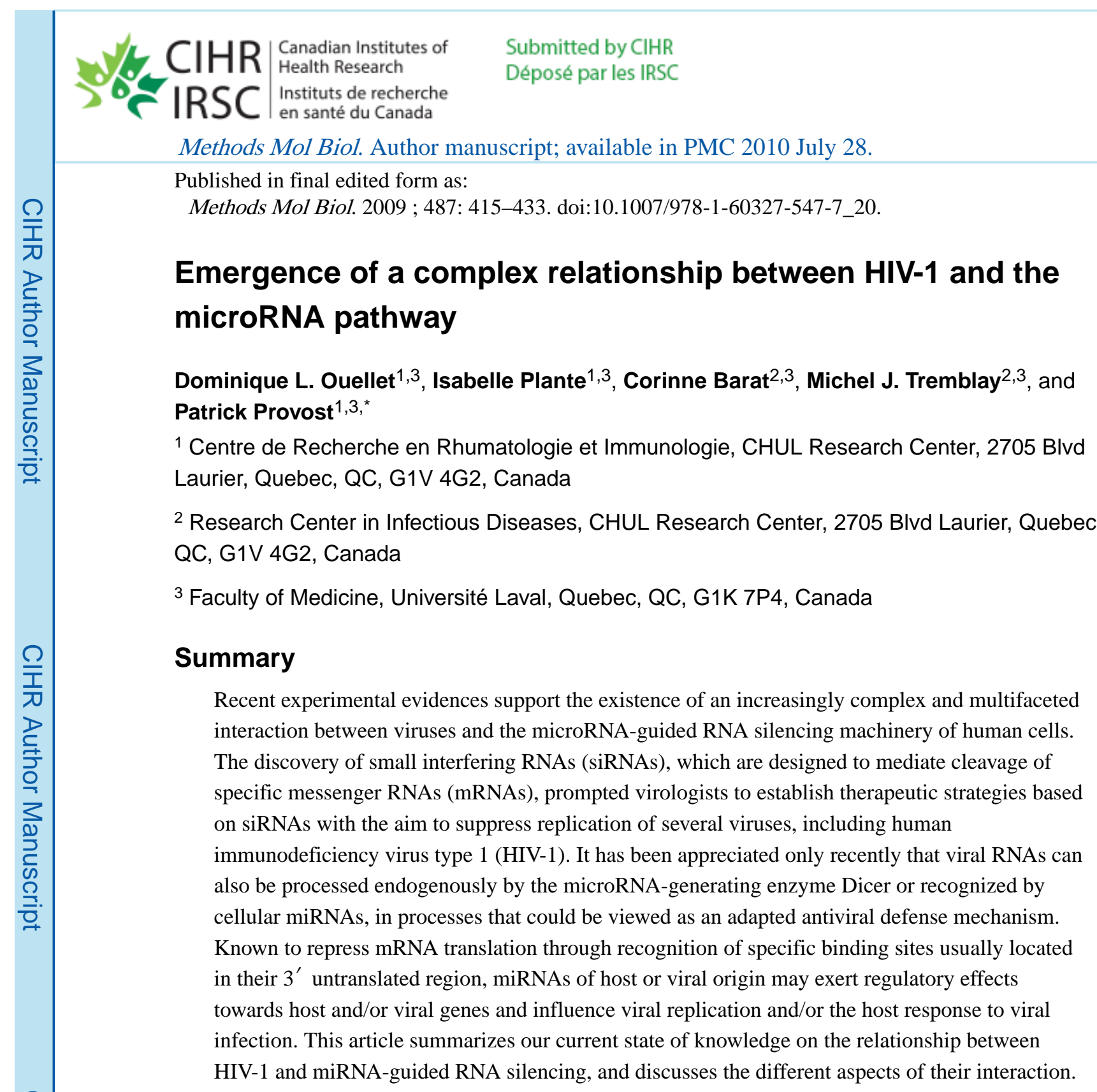

\title{
Keywords
}

HIV-1; RNA silencing; microRNA; small interfering RNA; gene expression

\section{Biology of MicroRNAs}

\subsection{MicroRNAs as Key Regulators of Gene Expression}

MicroRNAs (miRNAs) are short 21 to 24-nucleotides (nt) RNA species expressed in most eukaryotes and known as key regulators of gene expression that act through imperfect basepairing with their target messenger RNA (mRNA) $(1,2)$. According to the latest update of

*Corresponding author: Patrick Provost, PhD, Centre de Recherche en Rhumatologie et Immunologie, 2705 Blvd Laurier, Local T1-49, Ste-Foy, Quebec, G1V 4G2 Canada, Phone: 14186564141 (ext. 48842), Fax: 14186542765 ,

patrick.provost@crchul.ulaval.ca. 
miRBase (release 10.0, August 2007), the repository of miRNA data on the web, more than 556 human miRNA sequences have been identified so far, among a total of 5071 entries $(3,4)$. A recent study suggested that miRNAs may regulate up to $92 \%$ of the genes in human (5)! The panoply of small gene regulatory RNAs has recently gained in complexity with the discovery in eukaryotic organisms of additional classes distinct from miRNAs, such as repeat-associated small interfering RNAs (rasiRNAs) (6), tiny noncoding RNAs (tncRNAs) (7) and Piwi-interacting RNAs (piRNAs) (6).

\subsection{The Endogenous MicroRNA-Based RNA Silencing Machinery}

Encoded by the genome of most eukaryotes examined so far, miRNA genes are transcribed by RNA polymerase (pol) II into stem-loop structured primary miRNAs (pri-miRNAs). Harboring a $5^{\prime} \mathrm{m} 7 \mathrm{G}$ cap and a $3^{\prime}$ poly(A) tail $(8,9)$, these pri-miRNAs are then trimmed into $\sim 60-70$-nt miRNA precursors (pre-miRNAs) (see Figure 1A) by the nuclear ribonuclease (RNase) III Drosha (10), acting in concert with the DiGeorge syndrome critical region 8 (DGCR8) protein within the microprocessor complex (11-14). The pre-miRNAs are subsequently exported to the cytoplasm via Exportin-5 (15-18) and the base of their stem recognized by the PAZ domain of Dicer (19). Acting as an intramolecular dimer, the RNase IIIa and IIIb domains cleave the stem at the base of the loop to generate a miRNA:miRNA* duplexes (19-22). Dicer was recently shown to operate with the transactivating response RNA-binding protein (TRBP) (23) within a pre-miRNA processing complex $(24,25)$.

Following a strand selection and separation step, which is based on the thermodynamic stability of the RNA duplex(26), the miRNA strand ( 21 to 24-nt) with the least stable $5^{\prime}$ end pairing (called the guide strand) is incorporated into effector miRNA-containing ribonucleoprotein (miRNP) complexes, containing Argonaute 2 (Ago2), TRBP and Dicer (25), and guiding them towards specific messenger RNAs (mRNAs). The opposite miRNA* strand (also called passenger strand) is encountered much less frequently and is presumably degraded (27). miRNA assembly on specific mRNA sequences may be facilitated by the fragile $\mathrm{X}$ mental retardation protein, which can accept and use miRNAs derived from Dicer (28). The targeted mRNA will be primarily subjected to translational repression, although mRNAs containing partial miRNA complementary sites may also be targeted for degradation in vivo (29). These regulatory events may occur at specific cytoplasmic foci referred to as processing bodies (P-bodies) $(30,31)$, or GW182-containing bodies (GWbodies) (32), which are formed as a consequence of the presence of miRNAs (33). P-bodies are enriched in proteins involved in RNA-mediated gene silencing, such as Ago2 (30), mRNA degradation (34), and nonsense-mediated mRNA decay $(35,36)$

\subsection{Biological Roles of MicroRNAs}

miRNAs have been shown to control various processes, such as cell proliferation and apoptosis in flies, and hematopoietic cell differentiation in mice (37). Their biological role is linked to their ability to initially repress translation of specific mRNAs, although a case of enhancement of translation mediated by miRNAs/miRNPs during the cell cycle was recently reported (38). The action of miRNAs is accomplished through recognition of specific miRNA binding sites usually located in the mRNA $3^{\prime}$ untranslated region (UTR), thereby inhibiting translation initiation (39). Because recognition by miRNAs is mainly based on imperfect sequence complementarity, the identification of their physiological mRNA targets 
is difficult to predict and is rather arduous. Characterization of a few experimentally validated miRNA:mRNA interactions (eg, let-7 and lin-41) (40), allowed to establish a context in which this interaction is favored. For example, the critical miRNA:mRNA pairing region, referred to as the "miRNA seed", involves nt 2 to 8 of the miRNA in the $5^{\prime}$ to $3^{\prime}$ orientation. Although it appears to be less important, pairing of the miRNA $3^{\prime}$ region may compensate a weaker binding of the $5^{\prime}$ region (40). A better understanding of mRNA recognition by miRNAs helped develop bioinformatic approaches that have proven to be instrumental for identifying potential miRNA targets and initiating characterization of miRNA function.

\subsection{A role for Small RNAs in Antiviral Host Defenses}

In addition to fulfilling important gene regulatory functions in their eukaryotic hosts, small RNAs may also help defend against invasion of the host genome by RNAs of foreign origin, such as viruses. Initial evidences for such a role came from observations made by plant biologists. Indeed, while investigating the natural antiviral defense mechanism known as posttranscriptional gene silencing (PTGS), Hamilton and Baulcombe detected the presence of antisense viral RNA of 25-nt in virus-infected plants by Northern blot (41). The authors noted that these small RNAs, which were later found to originate from viral double-stranded RNA (dsRNA) processing by Dicer or DICER-LIKE 1 (DCL1 in Arabidopsis) (42), were long enough to convey sequence specificity and suggested their probable role in limiting virus infection in plants. The antiviral function of small RNAs and their biosynthetic machinery in plants has recently been extended to insects, nematodes $(43,44)$ and mammals.

\section{Biology of HIV-1}

\subsection{HIV-1 Life Cycle}

HIV-1 is an enveloped virus that binds cell receptor CD4 and most common coreceptors C$\mathrm{X}-\mathrm{C}$ motif receptor 4 (CXCR4) in lymphocytes or C-C motif receptor 5 (CCR5) in macrophages. For more details about HIV-1 life cycle, please refer to recent reviews (4547). Viral gp120 is responsible for binding, whereas gp41 is essential for fusion of the viral particle to the cellular membrane. The genome of HIV-1 is composed of two identical single stranded $9.6 \mathrm{~kb}$ RNA molecules. After cell entry and uncoating, the viral genetic material is reverse transcribed (RT) into cDNA by the HIV-1 viral RT enzyme and integrated as doublestrand DNA into the host genome before directing viral gene expression. HIV-1 relies heavily on the cellular transcription and translation machineries for the synthesis of viral genomic RNA and proteins. As partly illustrated in Figure 1A, the full-length RNA is transcribed by RNA pol II and serves both as genomic RNA and as a template for expression of the structural proteins Gag and Gag/Pol. The singly spliced $4 \mathrm{~kb}$ mRNA encodes Vif, Vpr, Vpu and Env and the fully spliced $2 \mathrm{~kb}$ mRNAs encode Tat, Rev and Nef. Some HIV-1 RNA transcripts are produced from the DNA bipartite element, known as the inducer of shorts transcripts (IST), located downstream of the start site of transcription into the long terminal repeat $(48,49)$. The subpopulation of non-polyadenylated shorts transcripts have heterogenous $3^{\prime}$ nucleotide ends situated around position +60 and contains the TransActivation Responsive (TAR) element (49). All these RNA species adopt complex and dynamic secondary structures that are reminiscent of pre-miRNAs and thus could potentially 
be targeted by the host miRNA-guided RNA silencing machinery. Although the high variability of the HIV-1 genome gives rise to a multitude of RNA folding possibilities, a number of structures are very well conserved because of their essential function in the virus life cycle. Among these are the dimerization site, TAR region and Rev-Responsive Element (RRE). These elements all have in common dsRNA structures (dimerization or stem-loop), which may potentially be processed into miRNAs. Whether these structures are recognized and processed by the Drosha.DGCR8 or Dicer-TRBP complexes remains to be determined.

\subsection{HIV-1 Dimerization Initiation Site}

In virus particles, the genome consists of two identical molecules of RNA that are noncovalently linked near their $5^{\prime}$ ends. The dimerization process involves a series of conformational changes of the untranslated leader region in which a first structure referred as the kissing-loop complex is rearranged into a more extended molecular duplex (50) that can be targeted by synthetic molecules for potential inhibition of the dimerization initiation site (DIS). However, these conformations possess a number of dimer RNA molecules and stem-loop structures that could potentially be recognized by Drosha and/or Dicer, whereby the latter preferentially cleaves dsRNAs at their termini (22), to generate miRNAs.

\subsection{HIV-1 TAR}

The TAR region is a 59-nt stem-bulge-loop structure located at the $5^{\prime}$ end of all spliced and unspliced HIV-1 transcripts found in the nucleus and cytoplasm, which is essential for efficient viral transcription. TAR is a short leader RNA structure targeted by the viral transactivating protein Tat that is known to act at the RNA level to enhance virus gene expression by more than 100 fold (51). Upon binding to the trinucleotide pyrimidine-rich bulge of TAR, Tat recruits the positive transcription-elongation factor $\mathrm{b}(\mathrm{P}-\mathrm{TEFb})$, a complex made of cyclin T1 and the cyclin dependent kinase 9 (CDK9), to the initiation complex. The CDK9 then phosphorylates the C-terminal domain (CTD) of the RNA polymerase II, which promotes the formation of an efficient elongation transcription complex (52). Apart from this nuclear-based function, TAR is also important after RNA export to the cytoplasm since it inhibits translation by two mechanisms, i.e. through a direct block of translation initiation by its secondary structure and by activation of the dsRNA binding protein kinase R (PKR) which, in turn, phosphorylates the eukaryotic initiation factor 2 alpha (eIF2a) leading to an arrest of translation initiation. Both of these negative effects are alleviated by TRBP, which inhibits PKR (53) and releases the translational block due to the TAR structure (54). (For more details about HIV-1 TAR RNA and Tat protein, please refer to these reviews $(52,55,56))$

\subsection{HIV-1 RRE}

The RRE domain is a large RNA structure present in all $9 \mathrm{~kb}$ and $4 \mathrm{~kb}$ RNAs, located within the Env intron. Through its interaction with RRE, Rev protein is responsible for the nuclear export of these unspliced or singly spliced RNAs. In the absence of Rev, these RNAs are sequestered in the nucleus and only the multiply spliced $2 \mathrm{~kb}$ RNA encoding the regulatory proteins Tat, Rev and Nef are exported in the cytoplasm and translated. The interaction between Rev and RRE promotes the transition between this early phase of the viral life cycle to the late phase where structural proteins are produced (57). The RRE is a $351 \mathrm{nt}$ complex 
structure that comprises 5 stem-loop structures on which Rev assembles as a multimeric complex $(58,59)$. This structure may resemble pri-miRNAs, which are often composed of multiple stem-loop structures, and represent a very good candidate for the source of viral miRNA. Although it is interesting to note that, like TAR, RRE interacts with TRBP (53), the latter does not appear to influence the effect of Rev on RRE-containing sequence.

\section{Relationship Between HIV-1 and RNA Silencing}

\subsection{Small RNAs Directed Against HIV-1}

Small interfering RNAs (siRNAs) are synthetic 21-nt RNA duplexes that have been designed to mimic the endogenous miRNAs or DICER-generated siRNAs. Their efficiency in downregulating expression of specific genes in cultured mammalian cells (60) established the basis for the use of siRNAs or RNA interference (RNAi) technology in therapeutics. This strategy was exploited successfully to inhibit the replication of several viruses, including HIV-1 (see Figure 2). Approaches based on siRNA targeting of host genes have been also used to restrict HIV-1 production (61). This anti-HIV-1 therapy is one of the RNA-based strategies that include antisenses, ribozymes and aptamers. Some of them are currently being tested in clinical trials (62).

Short hairpin RNA (shRNA) precursors are also used to trigger RNAi against HIV-1. shRNAs are produced either from mammalian expression vectors or viral vectors bearing H1, U6 or 7SK promoters for expression (63) (see Figure 2). The gene inhibitory potency of shRNAs, which requires prior processing into effector siRNAs by Dicer, is superior to siRNAs themselves, presumably because they enter the miRNA pathway upstream to siRNAs. Such approaches may be combined, for example, with protein-based anti-HIV-1 agents, for increased therapeutic efficiency (64).

Although RNAi-based antiviral therapies are promising, HIV-1 has been shown to escape RNAi induced by a specific siRNA. In these cases, the emergence of mutants was observed, either showing nucleotide substitutions or deletions within the targeted sequence (65), or evolving an alternative structure in its RNA genome occluding the siRNA binding site (66). A single substitution in the targeted sequence is sometimes sufficient to abolish the antiviral activity of siRNAs (67). Such problem may be circumvented by targeting the most conserved sequences at multiple locations in the HIV-1 genome (68).

\subsection{Viral MicroRNAs}

The observed sequence-specific HIV-1 RNA degradation induced by siRNAs implies that certain HIV-1 RNA sequences are accessible to the RNA silencing machinery in vivo. Likely to be applicable to other viruses, this concept is supported by the demonstrated improvement of RNA-induced silencing complex (RISC)-mediated target RNA cleavage when the target site access is increased (69). Accessibility to the viral RNA is mandatory for an antiviral function of the miRNA-guided RNA silencing pathway, a research theme that has attracted the interest of several laboratories. A research group led by Thomas Tuschl was the first to investigate the role of RNA silencing in human cells infected with viruses. Recording the small RNA profile of a Burkitt's lymphoma cell line latently infected with Epstein-Barr 
virus (EBV), they found that this large DNA virus expresses several miRNAs (70).

Bioinformatic analysis of the genomic sequences flanking the cloned RNAs, which were detectable by Northern blot, unveiled fold-back structures characteristics of miRNA precursors. As for plant virus-derived siRNAs (71), EBV miRNAs may originate predominantly from Dicer processing of highly structured single-stranded RNA. EBV is now known to express in latently infected cells at least 17 distinct miRNAs that are originating from two clusters located in the introns of the viral BART and adjacent BHRF1 genes. Differential regulation of EBV miRNA expression is observed and implies distinct roles during infection of different human tissues (72). Recently, EBV LMP1 was discovered as a target for miRNAs derived from BART cluster 1. This protein is implicated in the activation of cell signaling and gene expression in infected cells (73).

Using similar approaches, investigation of several other viruses identified miRNAs encoded in the Kaposi's sarcoma-associated herpesvirus (KSHV or HHV8), mouse gammaherpesvirus 68 and human cytomegalovirus (also called HHV5) (74). However, viral miRNAs derived from HIV-1 were neither predicted (using an algorithm identifying genomic regions that may assume a secondary structure similar to that of pri- or premiRNAs) nor found among 260 cloned miRNA sequences derived from HeLa cells stably expressing CD4 and CXCR4, and infected by HIV-1, isolate Bru (LAV-1) (74). These findings suggested that HIV-1 may effectively hide its highly structured RNA from RNase III cleavage.

\subsection{HIV-1-Derived MicroRNAs}

However, this assertion is being challenged, as concurrent studies about HIV-1 miRNAs have been reported. Using a computational method designed to uncover well-ordered folding patterns in nucleotide sequences, five candidate pre-miRNAs encoded by different regions of the HIV-1 genome were flagged (75). Omoto and colleagues (76) reported a miRNA (miRN367) derived from the nef region, an accessory gene partially overlapping with the $3^{\prime}$ long terminal repeat (LTR). This HIV-1 miRNA could be detected by Northern blot analysis in MT-4 T cells persistently infected with HIV-1 IIIB and cloned from a $~ 25$-nt RNA subpopulation. Overexpression of miR-N367, which shows perfect complementarity with nef, seemed to suppress HIV-1 LTR-driven transcription in reporter gene assays (77) (see Figure 1B), suggesting that this nef-derived miRNA could act as a negative regulator of HIV-1 transcription. The biogenesis and action of this particular miRNA require further investigations.

Another study reported that the HIV-1 RNA genome also encodes an siRNA derived from the env gene (78). The authors observed that two RNA strands forming a perfect 19-bp duplex, and joined by an extended 198-nt loop, could be converted into siRNAs upon incubation with recombinant Dicer in vitro. A probe specific for the viral siRNA detected a 24-nt signal not seen in mock-infected cells by Northern blot analysis (78). Overexpression of this viral siRNA effectively reduced Env mRNA levels and viral replication, whereas its neutralization with complementary 2' O-methyl oligonucleotides led to a dose-dependent increase in HIV-1 replication in human cells (78). These results suggest that an HIV-1derived siRNA can reduce virus production. 
Another natural HIV-1 RNA structure, the TAR element, was recently reported to be cleaved by Dicer to generate a miRNA that have been suggested to recruit the histone deacetylase HDAC-1 to the HIV-1 LTR promoter to silence transcription by chromatin remodeling (79) (see Figure 1B), a concept that has been proposed previously (80). The authors hypothesize that this sequence of events may suppress transcription of viral as well as cellular genes, thereby influencing particular steps of HIV-1 pathogenesis, such as latency.

Whether or not HIV-1 miRNAs are effectively produced in infected cells and fulfill important biological roles warrants further experimental validation and confirmation. A recent study by Lin and Cullen (81) is challenging the existence of miRNAs derived from primate retroviruses, such as HIV-1 and human T cell leukemia/lymphoma virus type 1 (HTLV-1), and is questioning the suppressive properties of HIV-1 Tat on RNA silencing that has been reported by Bennasser and colleagues (78) (see Figure 1C). It may be that the identification of some miRNAs are restricted to specific viral strains or that miRNAs may escape detection by standard small RNA cloning strategies, since methylation of the $2^{\prime}$ hydroxyl of the terminal ribose significantly reduces the cloning efficiency of silencingassociated small RNAs (82). This would explain some of the discrepancies observed between laboratories using different techniques to identify viral miRNAs.

\subsection{Biosynthetic Mechanism of HIV-1 MicroRNAs}

The controversy surrounding the existence of miRNAs derived from HIV-1 may be related to their levels of expression that may be barely detectable using the techniques currently available. If their existence is proven unequivocally, their biosynthesis would merit due mechanistic considerations. For instance, are these viral miRNAs processed by the successive action of Drosha and Dicer like cellular miRNAs, by Dicer only or, as in plants, by an RNAi pathway adapted to viruses? How does the cleavage of an RNA substrate flanked by genomic single-stranded RNA sequences occur, knowing the preference of Dicer for RNA duplexes bearing terminal 2-nt 3' overhangs (22)? Is that processing linked in any ways to the infectious state, considering that the latency period of HIV-1 is associated with the expression of aborted mRNA transcripts? How does the presence of an exceedingly expanded loop in env siRNA precursor influence its processing? Is the expression level of viral miRNAs related to the relatively inefficient processing of HIV-1 dsRNA substrates by RNases III and/or to the limited access to a structure embedded within the HIV-1 RNA? Although regions of the HIV-1 genome show structures relatively close to that of pri- or premiRNAs, the fact that they are decorated with many cellular and viral proteins may also affect their recognition and processing by Drosha and/or Dicer.

\subsection{Biological Significance of HIV-1 MicroRNAs}

The possibility that HIV-1 miRNAs exert significant biological roles and directly influence viral pathogenesis and persistence in human cells is appealing. The results of recent studies have suggested a role for HIV-1 miRNAs in transcriptional repression induced either by miR-N367 (76) or TAR miRNA binding to the LTR-driven promoter (79). Cellular mRNAs that could potentially be regulated by these viral miRNAs have been tentatively identified (75). Investigation of the human and viral genes, as well as the processes possibly regulated 
by HIV-1 miRNAs, which have been the subject of speculations, awaits their prior experimental confirmation and validation.

\subsection{Cellular MicroRNAs and HIV-1 infection}

A few years ago, candidate HIV-1 genes that could be controlled by host miRNAs have been predicted in view of thermodynamically favorable miRNA:target pairing (83). In addition, changes in miRNA expression profiles, i.e. downregulation of a large pool of miRNAs, have been observed in human HeLa cells transfected with the infectious molecular clone pNL4-3 (84). A more recent study explored the importance of the miRNA pathway in the control of HIV-1 replication (85). Using siRNAs against Drosha and Dicer in peripheral blood mononuclear cells (PBMCs) from HIV-1-infected patients, Triboulet et al. (85) noticed a faster virus replication kinetic in Drosha- or Dicer-depleted cells, as compared to cells treated with a control siRNA. The authors also confirmed in latently infected U1 cells that both Drosha and Dicer contribute to the suppression of HIV-1 replication.

HIV-1 infection was also associated with either up- or down-regulation of specific miRNA clusters. For instance, the miR-17/92 cluster, which encode for 7 miRNAs, among which miR-17-5p and miR-20 may target the histone acetyltransferase and HIV-1 Tat cofactor p300/CBP-associated factor (PCAF), was substantially decreased (see Figure 1D). The authors proposed that this gene regulatory axis may help understand how latent virus reservoir could be activated.

A more recent study explored the possible contribution of cellular miRNAs to HIV-1 infection. Huang et al. (86) showed that the $3^{\prime}$ UTR of almost all HIV-1 mRNA produced during latency in resting primary $\mathrm{CD}^{+} \mathrm{T}$ lymphocytes contain a $1.2-\mathrm{kb}$ fragment that can be recognized by cellular miRNAs, with a negative impact on viral protein production (see Figure 1E). Combined with the relatively inefficient synthesis of Tat and Rev, miRNAs harbored by resting $\mathrm{CD} 4^{+} \mathrm{T}$ cells may participate in post-transcriptional regulation of HIV-1 mRNA and contribute to keep the virus in its latency phase, as observed in patients with suppressive highly active antiretroviral therapy (HAART) (86). These new elements contribute to our understanding of the molecular basis of viral latency and help us design therapeutic strategies aimed at purging HIV-1-infected patients of the quiescent virus.

\subsection{HIV-1, RNA Silencing and RNA Editing}

The susceptibility of viral RNAs to RNases III may also be modified by structural changes produced by adenosine deaminases that act on RNA (ADARs) $(87,88)$. The predominant form of RNA editing in human consists in the specific conversion of adenosine (A) into inosine (I) within largely double-stranded cellular and viral RNAs [reviewed in (89)]. A-to-I RNA editing may thus alter base pairing of a dsRNA substrate and reduce its susceptibility to Dicer cleavage, preventing it from initiating RNAi (87). Several viral genomes or transcripts show sequence changes consistent with such modification, including HIV-1. Indeed, TAR was previously reported to be a substrate for ADAR in Xenopus Oocytes and edited in a process dependent on Tat (90). Whether editing of viral RNAs may lead to viral persistence, as speculated previously (89), remains to be confirmed. 
Another group of deaminases from the APOBEC 3 family has been reported to counteract HIV-1 replication. For example, APOBEC3G is incorporated into HIV-1 particles and acts to restrict HIV-1 replication in infected cells by deaminating $\mathrm{dC}$ to $\mathrm{dU}$ in the first (minus)strand cDNA replication intermediate during the viral reverse transcription process, (91) which is correlated with a G-to-A modification of the second (positive)-strand. Despite its action on cDNA, APOBEC3 family members may induce mutations in the HIV-1 genomic DNA prior to its integration and thereby contribute to a pool of mutant RNA transcripts (92). The viral accessory protein Vif is known to be an inhibitor of APOBEC3 (93). The effect of these edition events on the generation of mutations in dsRNA structures remains to be elucidated.

\subsection{Interaction Between HIV-1 Tat and the MicroRNA-Based RNA Silencing Machinery}

In addition to protein-RNA and RNA-RNA interactions, recent studies have revealed an intriguing link between protein components involved in HIV-1 pathogenesis and RNA silencing, such as the virally-encoded Tat protein and the cellular TRBP.

Overexpression of Tat in mammalian cells was shown to attenuate silencing of reporter genes indu6ced by short hairpin RNAs (shRNAs), but not siRNA (78). Knowing that the former elicits RNAi upon Dicer processing, the authors investigated and determined that Tat could inhibit Dicer activity in vitro (see Figure 1C). However, prior to qualifying HIV-1 Tat as a proven inhibitor of Dicer function, it would be prudent (i) to determine if the Dicer inhibitory effect of Tat can be extended in vivo and occurs at physiological expression levels, (ii) to confirm that the observed inhibitory effects of Tat are specific and not due to random binding to dsRNAs, (iii) to verify if RNAi proceeds normally in the context of HIV-1 infection, and (iii) to assess whether Dicer function is indeed inhibited by HIV-1 in infected cells. Whether HIV-1 Tat suppresses RNA silencing remains controversial. (81).

\subsection{TRBP and PACT Function in RNA Silencing}

HIV-1 TAR RNA-binding protein (TRBP) was originally discovered as a cellular protein that cooperates synergistically with viral Tat function and enhances transactivation of the HIV-1 5' LTR (see Figure 1A) (23). TRBP is also known to inhibit the interferon (IFN)induced dsRNA-regulated protein kinase R (PKR) (94), and to be involved in miRNAguided RNA silencing, more specifically, in assisting Dicer function within a pre-miRNA processing complex $(24,25)$. Immunoprecipitation approaches identified TRBP as a Dicerinteracting protein $(24,25)$. The Dicer-binding region on TRBP could be delineated to its third C-terminal dsRNA-binding domain (dsRBD) and depletion of TRBP was found to negatively affect pre-miRNA processing using cell extracts in vitro (24).

Similar to TRBP, PKR-activating protein (PACT) (95) has been found to interact with the Nterminal domain of Dicer via its third dsRBD (96). In fact, PACT can bind directly to TRBP and form a ternary complex with Dicer and TRBP to facilitate the production of siRNAs by Dicer. Knockdown of both TRBP and PACT in cultured mammalian cells led to a significant inhibition of gene silencing mediated by shRNAs, but not by siRNAs, suggesting that TRBP and PACT function primarily at the step of siRNA production (97). Despite exerting opposite effects on PKR, PACT and TRBP may thus play a similar, possibly redundant, role 
in miRNA biogenesis and function. The exact role of PACT in HIV-1 pathogenesis and RNA silencing remains to be clearly defined.

\subsection{A Dual Role for TRBP - Implications for HIV-1}

TRBP may thus exert a dual role in HIV-1 pathogenesis and RNA silencing, as recently discussed (98). The requirement of TRBP to achieve a higher virus production may have forced the virus to evolve under selective pressure from the RNA silencing machinery. There is a possibility that TAR and RRE RNA structures could also compete with Dicer for TRBP binding, and thus inhibit RNA silencing (98). The delicate balance thereby created may have conferred to HIV-1 the ability to replicate in TRBP-expressing cells and be responsible, to some extent, for the low virus load and persistence in HIV-1-infected individuals. Pharmacological interventions aimed at dissociating TRBP functions may represent a relevant therapeutic area to combat the HIV-1 pandemic.

\subsection{Perspectives for HIV-1}

A number of studies published recently have provided key insights into the increasingly complex interaction between HIV-1, miRNAs and host RNA silencing machineries. It has been known for that HIV-1 induces drastic changes in gene expression programming of infected cells. With the recent idea that HIV-1 may encode miRNAs, the identification and validation of the complete HIV-1 miRNA array as well as their cellular and viral mRNA targets, which pose a considerable challenge, may significantly improve our understanding of HIV-1 pathogenesis. In particular, it may help determine to what extent the perturbed gene expression profiles in HIV-1-infected cells (99-101) can be related to virus-derived miRNAs and how it ultimately influences viral replication, latency as well as the efficiency of host defenses. This raises the attractive hypothesis that HIV-1 replication may result, at least in part, from a delicate balance between the structural requirements to support HIV-1 replication versus the potential beneficial role of HIV-1 miRNAs in conferring an advantage to the virus and/or thwarting host defenses.

\subsection{Applicability to Other Viruses}

The various aspects of the interaction between HIV-1 and the RNA silencing machinery may also be applicable to other viruses of global importance for human health. In turn, mechanisms described for other viruses may ultimately be transposed to HIV-1. A few examples that may be relevant include (i) herpesvirus Kaposi's sarcoma-associated herpesvirus (KSHV), which encodes as much as 11 distinct miRNAs that may play critical roles in establishment and/or maintenance of KHSV latent infection (102), (ii) EBV, which expresses miRNAs from its BART and BHRF transcripts that either target the viral protein LMP1 (73) or characterize type III latency in infected B lymphocytes (103), (iii) simian virus 40 (SV40), which encodes miRNAs that regulate viral gene expression and reduce susceptibility to cytotoxic T cells (104), (iv) a cellular miRNA, miR-32, that was recently shown to restrict the accumulation of the retrovirus primate foamy virus type 1 (PFV-1) (105), and, in contrast, (v) an abundant miRNA specifically expressed in the human liver, miR-122, that has been shown to assist hepatitis $\mathrm{C}$ virus (HCV) replication through a genetic interaction with the $5^{\prime}$ noncoding region of the viral genome (106). 


\section{Conclusion}

Further investigation on the relationship between HIV-1 and RNA silencing pathways may unveil key aspects of host-pathogen interactions, provide new insights into the persistence of the virus in infected patients and offer novel basis for anti-HIV-1 therapies.

\section{Acknowledgments}

We express our gratitude to Gilles Chabot for graphic illustration. P. P. is a New Investigator of the Canadian Institutes of Health Research (CIHR) and Junior 2 Scholar from the Fonds de la Recherche en Santé du Québec. M.J.T. is the recipient of the Canada Research Chair in Human Immuno-Retrovirology (senior level). This work was financially supported by grant HOP-83069 from Health Canada/CIHR (P.P. and M.J.T.).

\section{References}

1. Zamore PD, Haley B. Ribo-gnome: the big world of small RNAs. Science. 2005; 309:1519-1524. [PubMed: 16141061]

2. Kim VN. MicroRNA biogenesis: coordinated cropping and dicing. Nat Rev Mol Cell Biol. 2005; 6:376-385. [PubMed: 15852042]

3. Griffiths-Jones S. The microRNA Registry. Nucleic Acids Res. 2004; 32:D109-111. [PubMed: 14681370]

4. Griffiths-Jones S, Grocock RJ, van Dongen S, Bateman A, Enright AJ. miRBase: microRNA sequences, targets and gene nomenclature. Nucleic Acids Res. 2006; 34:D140-144. [PubMed: 16381832]

5. Miranda KC, Huynh T, Tay Y, Ang YS, Tam WL, Thomson AM, Lim B, Rigoutsos I. A patternbased method for the identification of MicroRNA binding sites and their corresponding heteroduplexes. Cell. 2006; 126:1203-1217. [PubMed: 16990141]

6. Aravin AA, Lagos-Quintana M, Yalcin A, Zavolan M, Marks D, Snyder B, Gaasterland T, Meyer J, Tuschl T. The small RNA profile during Drosophila melanogaster development. Dev Cell. 2003; 5:337-350. [PubMed: 12919683]

7. Ambros V, Lee RC, Lavanway A, Williams PT, Jewell D. MicroRNAs and other tiny endogenous RNAs in C. elegans. Curr Biol. 2003; 13:807-818. [PubMed: 12747828]

8. Cai X, Hagedorn CH, Cullen BR. Human microRNAs are processed from capped, polyadenylated transcripts that can also function as mRNAs. Rna. 2004; 10:1957-1966. [PubMed: 15525708]

9. Lee Y, Kim M, Han J, Yeom KH, Lee S, Baek SH, Kim VN. MicroRNA genes are transcribed by RNA polymerase II. Embo J. 2004; 23:4051-4060. [PubMed: 15372072]

10. Lee Y, Ahn C, Han J, Choi H, Kim J, Yim J, Lee J, Provost P, Radmark O, Kim S, et al. The nuclear RNase III Drosha initiates microRNA processing. Nature. 2003; 425:415-419. [PubMed: 14508493]

11. Denli AM, Tops BB, Plasterk RH, Ketting RF, Hannon GJ. Processing of primary microRNAs by the Microprocessor complex. Nature. 2004; 432:231-235. [PubMed: 15531879]

12. Gregory RI, Yan KP, Amuthan G, Chendrimada T, Doratotaj B, Cooch N, Shiekhattar R. The Microprocessor complex mediates the genesis of microRNAs. Nature. 2004; 432:235-240. [PubMed: 15531877]

13. Han J, Lee Y, Yeom KH, Kim YK, Jin H, Kim VN. The Drosha-DGCR8 complex in primary microRNA processing. Genes Dev. 2004; 18:3016-3027. [PubMed: 15574589]

14. Landthaler M, Yalcin A, Tuschl T. The human DiGeorge syndrome critical region gene 8 and Its D. melanogaster homolog are required for miRNA biogenesis. Curr Biol. 2004; 14:2162-2167. [PubMed: 15589161]

15. Bohnsack MT, Czaplinski K, Gorlich D. Exportin 5 is a RanGTP-dependent dsRNA-binding protein that mediates nuclear export of pre-miRNAs. Rna. 2004; 10:185-191. [PubMed: 14730017] 
16. Brownawell AM, Macara IG. Exportin-5, a novel karyopherin, mediates nuclear export of doublestranded RNA binding proteins. J Cell Biol. 2002; 156:53-64. [PubMed: 11777942]

17. Lund E, Guttinger S, Calado A, Dahlberg JE, Kutay U. Nuclear export of microRNA precursors. Science. 2004; 303:95-98. [PubMed: 14631048]

18. Yi R, Qin Y, Macara IG, Cullen BR. Exportin-5 mediates the nuclear export of pre-microRNAs and short hairpin RNAs. Genes Dev. 2003; 17:3011-3016. [PubMed: 14681208]

19. Zhang H, Kolb FA, Jaskiewicz L, Westhof E, Filipowicz W. Single processing center models for human Dicer and bacterial RNase III. Cell. 2004; 118:57-68. [PubMed: 15242644]

20. Bernstein E, Caudy AA, Hammond SM, Hannon GJ. Role for a bidentate ribonuclease in the initiation step of RNA interference. Nature. 2001; 409:363-366. [PubMed: 11201747]

21. Provost P, Dishart D, Doucet J, Frendewey D, Samuelsson B, Radmark O. Ribonuclease activity and RNA binding of recombinant human Dicer. Embo J. 2002; 21:5864-5874. [PubMed: 12411504]

22. Zhang H, Kolb FA, Brondani V, Billy E, Filipowicz W. Human Dicer preferentially cleaves dsRNAs at their termini without a requirement for ATP. Embo J. 2002; 21:5875-5885. [PubMed: 12411505]

23. Gatignol A, Buckler-White A, Berkhout B, Jeang KT. Characterization of a human TAR RNAbinding protein that activates the HIV-1 LTR. Science. 1991; 251:1597-1600. [PubMed: 2011739]

24. Haase AD, Jaskiewicz L, Zhang H, Laine S, Sack R, Gatignol A, Filipowicz W. TRBP, a regulator of cellular PKR and HIV-1 virus expression, interacts with Dicer and functions in RNA silencing. EMBO Rep. 2005; 6:961-967. [PubMed: 16142218]

25. Chendrimada TP, Gregory RI, Kumaraswamy E, Norman J, Cooch N, Nishikura K, Shiekhattar R. TRBP recruits the Dicer complex to Ago 2 for microRNA processing and gene silencing. Nature. 2005; 436:740-744. [PubMed: 15973356]

26. Schwarz DS, Hutvagner G, Du T, Xu Z, Aronin N, Zamore PD. Asymmetry in the assembly of the RNAi enzyme complex. Cell. 2003; 115:199-208. [PubMed: 14567917]

27. Matranga C, Tomari Y, Shin C, Bartel DP, Zamore PD. Passenger-Strand Cleavage Facilitates Assembly of siRNA into Ago2-Containing RNAi Enzyme Complexes. Cell. 2005; 123:607-620. [PubMed: 16271386]

28. Plante I, Davidovic L, Ouellet DL, Gobeil LA, Tremblay S, Khandjian EW, Provost P. DicerDerived MicroRNAs Are Utilized by the Fragile X Mental Retardation Protein for Assembly on Target RNAs. J Biomed Biotechnol. 2006; 2006:64347. [PubMed: 17057366]

29. Bagga S, Bracht J, Hunter S, Massirer K, Holtz J, Eachus R, Pasquinelli AE. Regulation by let-7 and lin-4 miRNAs results in target mRNA degradation. Cell. 2005; 122:553-563. [PubMed: 16122423]

30. Liu J, Valencia-Sanchez MA, Hannon GJ, Parker R. MicroRNA-dependent localization of targeted mRNAs to mammalian P-bodies. Nat Cell Biol. 2005; 7:719-723. [PubMed: 15937477]

31. Teixeira D, Sheth U, Valencia-Sanchez MA, Brengues M, Parker R. Processing bodies require RNA for assembly and contain nontranslating mRNAs. Rna. 2005; 11:371-382. [PubMed: 15703442]

32. Eystathioy T, Chan EK, Tenenbaum SA, Keene JD, Griffith K, Fritzler MJ. A phosphorylated cytoplasmic autoantigen, GW182, associates with a unique population of human mRNAs within novel cytoplasmic speckles. Mol Biol Cell. 2002; 13:1338-1351. [PubMed: 11950943]

33. Eulalio A, Behm-Ansmant I, Schweizer D, Izaurralde E. P-body formation is a consequence, not the cause, of RNA-mediated gene silencing. Mol Cell Biol. 2007; 27:3970-3981. [PubMed: 17403906]

34. Eystathioy T, Jakymiw A, Chan EK, Seraphin B, Cougot N, Fritzler MJ. The GW182 protein colocalizes with mRNA degradation associated proteins hDcp1 and hLSm4 in cytoplasmic GW bodies. Rna. 2003; 9:1171-1173. [PubMed: 13130130]

35. Fukuhara N, Ebert J, Unterholzner L, Lindner D, Izaurralde E, Conti E. SMG7 is a 14-3-3-like adaptor in the nonsense-mediated mRNA decay pathway. Mol Cell. 2005; 17:537-547. [PubMed: 15721257]

36. Unterholzner L, Izaurralde E. SMG7 acts as a molecular link between mRNA surveillance and mRNA decay. Mol Cell. 2004; 16:587-596. [PubMed: 15546618] 
37. Bartel DP. MicroRNAs: genomics, biogenesis, mechanism, and function. Cell. 2004; 116:281-297. [PubMed: 14744438]

38. Vasudevan S, Tong Y, Steitz JA. Switching from Repression to Activation: MicroRNAs Can UpRegulate Translation. Science. 2007

39. Pillai RS, Bhattacharyya SN, Artus CG, Zoller T, Cougot N, Basyuk E, Bertrand E, Filipowicz W. Inhibition of translational initiation by Let-7 MicroRNA in human cells. Science. 2005; 309:15731576. [PubMed: 16081698]

40. Vella MC, Reinert K, Slack FJ. Architecture of a validated microRNA:target interaction. Chem Biol. 2004; 11:1619-1623. [PubMed: 15610845]

41. Hamilton AJ, Baulcombe DC. A species of small antisense RNA in posttranscriptional gene silencing in plants. Science. 1999; 286:950-952. [PubMed: 10542148]

42. Reinhart BJ, Weinstein EG, Rhoades MW, Bartel B, Bartel DP. MicroRNAs in plants. Genes Dev. 2002; 16:1616-1626. [PubMed: 12101121]

43. Lu R, Maduro M, Li F, Li HW, Broitman-Maduro G, Li WX, Ding SW. Animal virus replication and RNAi-mediated antiviral silencing in Caenorhabditis elegans. Nature. 2005; 436:1040-1043. [PubMed: 16107851]

44. Wilkins C, Dishongh R, Moore SC, Whitt MA, Chow M, Machaca K. RNA interference is an antiviral defence mechanism in Caenorhabditis elegans. Nature. 2005; 436:1044-1047. [PubMed: 16107852]

45. Han Y, Wind-Rotolo M, Yang HC, Siliciano JD, Siliciano RF. Experimental approaches to the study of HIV-1 latency. Nat Rev Microbiol. 2007; 5:95-106. [PubMed: 17224919]

46. Levy JA. HIV pathogenesis: knowledge gained after two decades of research. Adv Dent Res. 2006; 19:10-16. [PubMed: 16672543]

47. Suzuki Y, Craigie R. The road to chromatin - nuclear entry of retroviruses. Nat Rev Microbiol. 2007; 5:187-196. [PubMed: 17304248]

48. Sheldon M, Ratnasabapathy R, Hernandez N. Characterization of the inducer of short transcripts, a human immunodeficiency virus type 1 transcriptional element that activates the synthesis of short RNAs. Mol Cell Biol. 1993; 13:1251-1263. [PubMed: 8423790]

49. Ratnasabapathy R, Sheldon M, Johal L, Hernandez N. The HIV-1 long terminal repeat contains an unusual element that induces the synthesis of short RNAs from various mRNA and snRNA promoters. Genes Dev. 1990; 4:2061-2074. [PubMed: 2269426]

50. Huthoff H, Berkhout B. Multiple secondary structure rearrangements during HIV-1 RNA dimerization. Biochemistry. 2002; 41:10439-10445. [PubMed: 12173930]

51. Gatignol A, Jeang KT. Tat as a transcriptional activator and a potential therapeutic target for HIV-1. Adv Pharmacol. 2000; 48:209-227. [PubMed: 10987092]

52. Bannwarth S, Gatignol A. HIV-1 TAR RNA: the target of molecular interactions between the virus and its host. Curr HIV Res. 2005; 3:61-71. [PubMed: 15638724]

53. Park H, Davies MV, Langland JO, Chang HW, Nam YS, Tartaglia J, Paoletti E, Jacobs BL, Kaufman RJ, Venkatesan S. TAR RNA-binding protein is an inhibitor of the interferon-induced protein kinase PKR. Proc Natl Acad Sci U S A. 1994; 91:4713-4717. [PubMed: 7515177]

54. Dorin D, Bonnet MC, Bannwarth S, Gatignol A, Meurs EF, Vaquero C. The TAR RNA-binding protein, TRBP, stimulates the expression of TAR-containing RNAs in vitro and in vivo independently of its ability to inhibit the dsRNA-dependent kinase PKR. J Biol Chem. 2003; 278:4440-4448. [PubMed: 12475984]

55. Nekhai S, Jeang KT. Transcriptional and post-transcriptional regulation of HIV-1 gene expression: role of cellular factors for Tat and Rev. Future Microbiol. 2006; 1:417-426. [PubMed: 17661632]

56. Stevens M, De Clercq E, Balzarini J. The regulation of HIV-1 transcription: molecular targets for chemotherapeutic intervention. Med Res Rev. 2006; 26:595-625. [PubMed: 16838299]

57. Pollard VW, Malim MH. The HIV-1 Rev protein. Annu Rev Microbiol. 1998; 52:491-532. [PubMed: 9891806]

58. Lesnik EA, Sampath R, Ecker DJ. Rev response elements (RRE) in lentiviruses: an RNAMotif algorithm-based strategy for RRE prediction. Med Res Rev. 2002; 22:617-636. [PubMed: 12369091] 
59. Malim MH, Bohnlein S, Fenrick R, Le SY, Maizel JV, Cullen BR. Functional comparison of the Rev trans-activators encoded by different primate immunodeficiency virus species. Proc Natl Acad Sci U S A. 1989; 86:8222-8226. [PubMed: 2682638]

60. Elbashir SM, Harborth J, Lendeckel W, Yalcin A, Weber K, Tuschl T. Duplexes of 21-nucleotide RNAs mediate RNA interference in cultured mammalian cells. Nature. 2001; 411:494-498. [PubMed: 11373684]

61. Martinez MA, Gutierrez A, Armand-Ugon M, Blanco J, Parera M, Gomez J, Clotet B, Este JA. Suppression of chemokine receptor expression by RNA interference allows for inhibition of HIV-1 replication. Aids. 2002; 16:2385-2390. [PubMed: 12461411]

62. Rossi JJ, June CH, Kohn DB. Genetic therapies against HIV. Nat Biotechnol. 2007; 25:1444-1454. [PubMed: 18066041]

63. Amarzguioui M, Rossi JJ, Kim D. Approaches for chemically synthesized siRNA and vectormediated RNAi. FEBS Lett. 2005; 579:5974-5981. [PubMed: 16199038]

64. Li MJ, Kim J, Li S, Zaia J, Yee JK, Anderson J, Akkina R, Rossi JJ. Long-term inhibition of HIV-1 infection in primary hematopoietic cells by lentiviral vector delivery of a triple combination of anti-HIV shRNA, anti-CCR5 ribozyme, and a nucleolar-localizing TAR decoy. Mol Ther. 2005; 12:900-909. [PubMed: 16115802]

65. Das AT, Brummelkamp TR, Westerhout EM, Vink M, Madiredjo M, Bernards R, Berkhout B. Human immunodeficiency virus type 1 escapes from RNA interference-mediated inhibition. J Virol. 2004; 78:2601-2605. [PubMed: 14963165]

66. Westerhout EM, Ooms M, Vink M, Das AT, Berkhout B. HIV-1 can escape from RNA interference by evolving an alternative structure in its RNA genome. Nucleic Acids Res. 2005; 33:796-804. [PubMed: 15687388]

67. Sabariegos R, Gimenez-Barcons M, Tapia N, Clotet B, Martinez MA. Sequence Homology Required by Human Immunodeficiency Virus Type 1 To Escape from Short Interfering RNAs. J Virol. 2006; 80:571-577. [PubMed: 16378959]

68. Leonard JN, Schaffer DV. Computational design of antiviral RNA interference strategies that resist human immunodeficiency virus escape. J Virol. 2005; 79:1645-1654. [PubMed: 15650190]

69. Brown KM, Chu CY, Rana TM. Target accessibility dictates the potency of human RISC. Nat Struct Mol Biol. 2005; 12:469-470. [PubMed: 15852021]

70. Pfeffer S, Zavolan M, Grasser FA, Chien M, Russo JJ, Ju J, John B, Enright AJ, Marks D, Sander C, et al. Identification of virus-encoded microRNAs. Science. 2004; 304:734-736. [PubMed: 15118162]

71. Molnar A, Csorba T, Lakatos L, Varallyay E, Lacomme C, Burgyan J. Plant virus-derived small interfering RNAs originate predominantly from highly structured single-stranded viral RNAs. J Virol. 2005; 79:7812-7818. [PubMed: 15919934]

72. Cai X, Schafer A, Lu S, Bilello JP, Desrosiers RC, Edwards R, Raab-Traub N, Cullen BR. EpsteinBarr virus microRNAs are evolutionarily conserved and differentially expressed. PLoS Pathog. 2006; 2:e23. [PubMed: 16557291]

73. Lo AK, To KF, Lo KW, Lung RW, Hui JW, Liao G, Hayward SD. Modulation of LMP1 protein expression by EBV-encoded microRNAs. Proc Natl Acad Sci U S A. 2007; 104:16164-16169. [PubMed: 17911266]

74. Pfeffer S, Sewer A, Lagos-Quintana M, Sheridan R, Sander C, Grasser FA, van Dyk LF, Ho CK, Shuman S, Chien M, et al. Identification of microRNAs of the herpesvirus family. Nat Methods. 2005; 2:269-276. [PubMed: 15782219]

75. Bennasser Y, Le SY, Yeung ML, Jeang KT. HIV-1 encoded candidate micro-RNAs and their cellular targets. Retrovirology. 2004; 1:43. [PubMed: 15601472]

76. Omoto S, Ito M, Tsutsumi Y, Ichikawa Y, Okuyama H, Brisibe EA, Saksena NK, Fujii YR. HIV-1 nef suppression by virally encoded microRNA. Retrovirology. 2004; 1:44. [PubMed: 15601474]

77. Omoto S, Fujii YR. Regulation of human immunodeficiency virus 1 transcription by nef microRNA. J Gen Virol. 2005; 86:751-755. [PubMed: 15722536]

78. Bennasser Y, Le SY, Benkirane M, Jeang KT. Evidence that HIV-1 encodes an siRNA and a suppressor of RNA silencing. Immunity. 2005; 22:607-619. [PubMed: 15894278] 
79. Klase Z, Kale P, Winograd R, Gupta MV, Heydarian M, Berro R, McCaffrey T, Kashanchi F. HIV-1 TAR element is processed by Dicer to yield a viral micro-RNA involved in chromatin remodeling of the viral LTR. BMC Mol Biol. 2007; 8:63. [PubMed: 17663774]

80. Weinberg MS, Morris KV. Are viral-encoded microRNAs mediating latent HIV-1 infection? DNA Cell Biol. 2006; 25:223-231. [PubMed: 16629595]

81. Lin J, Cullen BR. Analysis of the interaction of primate retroviruses with the human RNA interference machinery. J Virol. 2007; 81:12218-12226. [PubMed: 17855543]

82. Ebhardt HA, Thi EP, Wang MB, Unrau PJ. Extensive 3' modification of plant small RNAs is modulated by helper component-proteinase expression. Proc Natl Acad Sci U S A. 2005; 102:13398-13403. [PubMed: 16157869]

83. Hariharan M, Scaria V, Pillai B, Brahmachari SK. Targets for human encoded microRNAs in HIV genes. Biochem Biophys Res Commun. 2005; 337:1214-1218. [PubMed: 16236258]

84. Yeung ML, Bennasser Y, Myers TG, Jiang G, Benkirane M, Jeang KT. Changes in microRNA expression profiles in HIV-1-transfected human cells. Retrovirology. 2005; 2:81. [PubMed: 16381609]

85. Triboulet R, Mari B, Lin YL, Chable-Bessia C, Bennasser Y, Lebrigand K, Cardinaud B, Maurin T, Barbry P, Baillat V, et al. Suppression of microRNA-silencing pathway by HIV-1 during virus replication. Science. 2007; 315:1579-1582. [PubMed: 17322031]

86. Huang J, Wang F, Argyris E, Chen K, Liang Z, Tian H, Huang W, Squires K, Verlinghieri G, Zhang H. Cellular microRNAs contribute to HIV-1 latency in resting primary CD4+ T lymphocytes. Nat Med. 2007; 13:1241-1247. [PubMed: 17906637]

87. Knight SW, Bass BL. The role of RNA editing by ADARs in RNAi. Mol Cell. 2002; 10:809-817. [PubMed: 12419225]

88. Tonkin LA, Bass BL. Mutations in RNAi rescue aberrant chemotaxis of ADAR mutants. Science. 2003; 302:1725. [PubMed: 14657490]

89. Bass BL. RNA editing by adenosine deaminases that act on RNA. Annu Rev Biochem. 2002; 71:817-846. [PubMed: 12045112]

90. Sharmeen L, Bass B, Sonenberg N, Weintraub H, Groudine M. Tat-dependent adenosine-to-inosine modification of wild-type transactivation response RNA. Proc Natl Acad Sci U S A. 1991; 88:8096-8100. [PubMed: 1896456]

91. Chelico L, Pham P, Calabrese P, Goodman MF. APOBEC3G DNA deaminase acts processively $3^{\prime}-->5^{\prime}$ on single-stranded DNA. Nat Struct Mol Biol. 2006; 13:392-399. [PubMed: 16622407]

92. Mbisa JL, Barr R, Thomas JA, Vandegraaff N, Dorweiler IJ, Svarovskaia ES, Brown WL, Mansky LM, Gorelick RJ, Harris RS, et al. Human immunodeficiency virus type $1 \mathrm{cDNAs}$ produced in the presence of APOBEC3G exhibit defects in plus-strand DNA transfer and integration. J Virol. 2007; 81:7099-7110. [PubMed: 17428871]

93. Kao S, Khan MA, Miyagi E, Plishka R, Buckler-White A, Strebel K. The human immunodeficiency virus type 1 Vif protein reduces intracellular expression and inhibits packaging of APOBEC3G (CEM15), a cellular inhibitor of virus infectivity. J Virol. 2003; 77:11398-11407. [PubMed: 14557625]

94. Daher A, Longuet M, Dorin D, Bois F, Segeral E, Bannwarth S, Battisti PL, Purcell DF, Benarous $\mathrm{R}$, Vaquero $\mathrm{C}$, et al. Two dimerization domains in the trans-activation response RNA-binding protein (TRBP) individually reverse the protein kinase $\mathrm{R}$ inhibition of HIV-1 long terminal repeat expression. J Biol Chem. 2001; 276:33899-33905. [PubMed: 11438532]

95. Patel RC, Sen GC. PACT, a protein activator of the interferon-induced protein kinase, PKR. Embo J. 1998; 17:4379-4390. [PubMed: 9687506]

96. Lee Y, Hur I, Park SY, Kim YK, Suh MR, Kim VN. The role of PACT in the RNA silencing pathway. Embo J. 2006; 25:522-532. [PubMed: 16424907]

97. Kok KH, Ng MH, Ching YP, Jin DY. Human TRBP and PACT directly interact with each other and associate with dicer to facilitate the production of small interfering RNA. J Biol Chem. 2007; 282:17649-17657. [PubMed: 17452327]

98. Gatignol A, Laine S, Clerzius G. Dual role of TRBP in HIV replication and RNA interference: viral diversion of a cellular pathway or evasion from antiviral immunity? Retrovirology. 2005; 2:65. [PubMed: 16253139] 
99. van't Wout AB, Lehrman GK, Mikheeva SA, O'Keeffe GC, Katze MG, Bumgarner RE, Geiss GK, Mullins JI. Cellular gene expression upon human immunodeficiency virus type 1 infection of CD4(+)-T-cell lines. J Virol. 2003; 77:1392-1402. [PubMed: 12502855]

100. Chun TW, Justement JS, Lempicki RA, Yang J, Dennis G Jr, Hallahan CW, Sanford C, Pandya P, Liu S, McLaughlin M, et al. Gene expression and viral prodution in latently infected, resting CD4+ T cells in viremic versus aviremic HIV-infected individuals. Proc Natl Acad Sci U S A. 2003; 100:1908-1913. [PubMed: 12552096]

101. Corbeil J, Sheeter D, Genini D, Rought S, Leoni L, Du P, Ferguson M, Masys DR, Welsh JB, Fink JL, et al. Temporal gene regulation during HIV-1 infection of human CD4+ T cells. Genome Res. 2001; 11:1198-1204. [PubMed: 11435401]

102. Cai X, Lu S, Zhang Z, Gonzalez CM, Damania B, Cullen BR. Kaposi's sarcoma-associated herpesvirus expresses an array of viral microRNAs in latently infected cells. Proc Natl Acad Sci U S A. 2005; 102:5570-5575. [PubMed: 15800047]

103. Xing L, Kieff E. Epstein-Barr virus BHRF1 micro- and stable RNAs during latency III and after induction of replication. J Virol. 2007; 81:9967-9975. [PubMed: 17626073]

104. Sullivan CS, Grundhoff AT, Tevethia S, Pipas JM, Ganem D. SV40-encoded microRNAs regulate viral gene expression and reduce susceptibility to cytotoxic T cells. Nature. 2005; 435:682-686. [PubMed: 15931223]

105. Lecellier CH, Dunoyer P, Arar K, Lehmann-Che J, Eyquem S, Himber C, Saib A, Voinnet O. A cellular microRNA mediates antiviral defense in human cells. Science. 2005; 308:557-560. [PubMed: 15845854]

106. Jopling CL, Yi M, Lancaster AM, Lemon SM, Sarnow P. Modulation of hepatitis C virus RNA abundance by a liver-specific MicroRNA. Science. 2005; 309:1577-1581. [PubMed: 16141076]

107. Ouellet DL, Perron MP, Gobeil LA, Plante P, Provost P. MicroRNAs in Gene Regulation: When the Smallest Governs It All. J Biomed Biotechnol. 2006; 2006:69616. [PubMed: 17057368] 


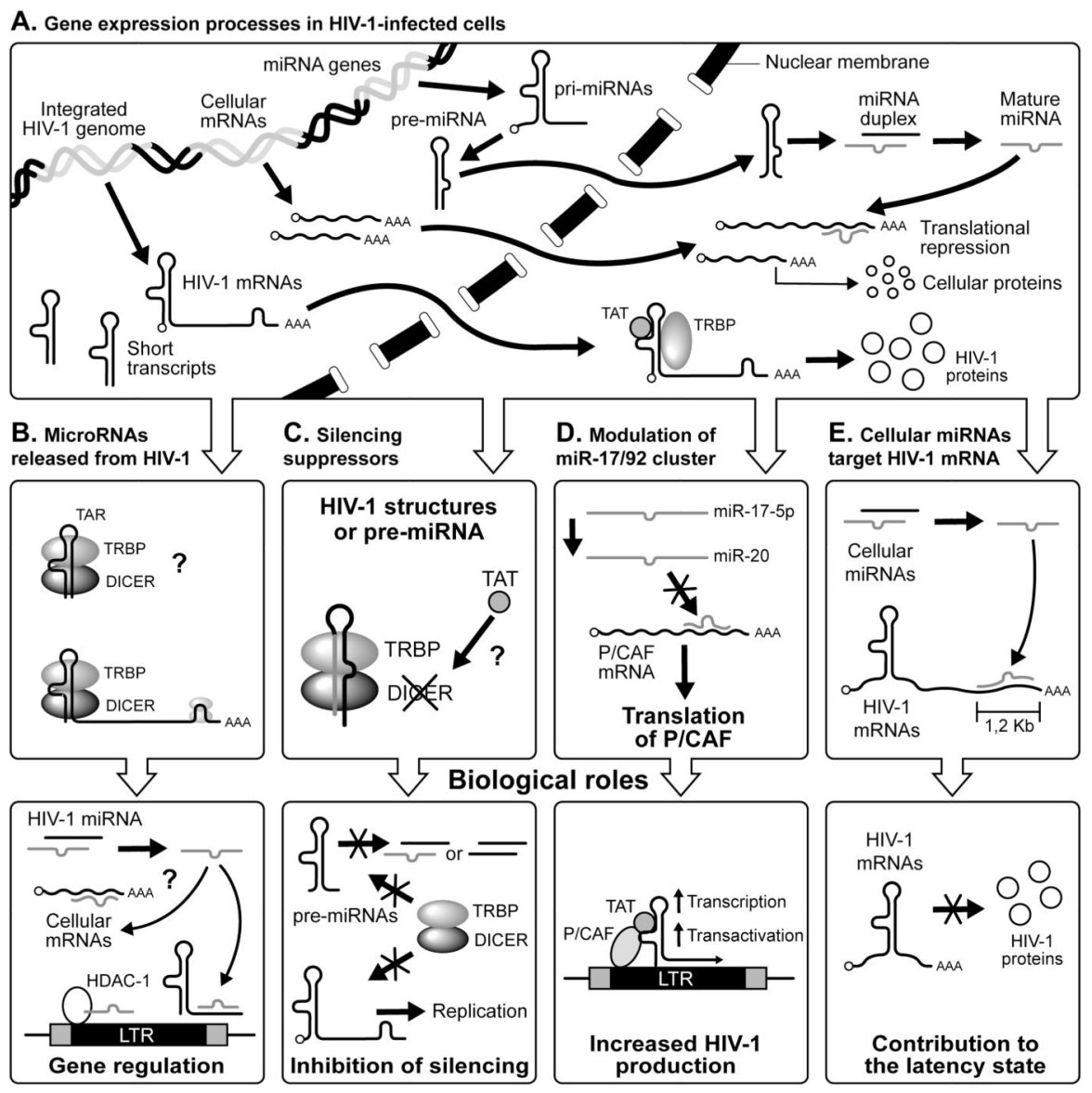

Figure 1.

Schematic representation of the intricate relationship between the miRNA silencing pathway and HIV-1. (A) In HIV-1-infected cells, full-length and short viral RNA transcripts are produced from the integrated HIV-1 genome. In these cells, like in normal non-infected cells, miRNA genes are transcribed into primary miRNAs (pri-miRNAs), which are trimmed into miRNA precursors (pre-miRNAs) in the nucleus. Pre-miRNAs are then exported to the cytoplasm where they are cleaved by Dicer to generate miRNA:miRNA* duplexes.

Following a strand selection and separation step, the mature miRNA is incorporated into effector complexes to mediate recognition and translational repression of specific cellular mRNAs, as reviewed recently (107). (B) Secondary structures in HIV-1 mRNAs may themselves be recognized and processed by Dicer into viral miRNAs or siRNAs, which could act on gene regulation in the cell, i.e by restricting LTR-driven transcription, recruit HDAC-1 to the LTR or repress cellular mRNAs. (C) TAR recognition by the Dicer-TRBP complex could be hampered by the viral transactivating protein Tat, which has been suggested to inhibit Dicer activity and could lead to suppression of silencing. This inhibitory effect of Tat remains under dispute. (D) In infected cells, HIV-1 could alter host gene expression through the modulation of miRNA expression. For instance, downregulation of the miR-17/92 cluster, via miR-17-5p and miR-20, has been reported to increase expression of a Tat cofactor, the P/CAF protein. This regulation could lead to an enhanced transactivation of the TAR element and could contribute to activate latent reservoirs. (E) A 
1.2-kb fragment present in the $3^{\prime}$ UTR of almost all HIV-1 mRNAs can be recognized by cellular miRNAs with a negative impact on viral protein production in $\mathrm{CD} 4^{+} \mathrm{T}$ cells, following a process that could contribute to keep the virus in its latency phase. 


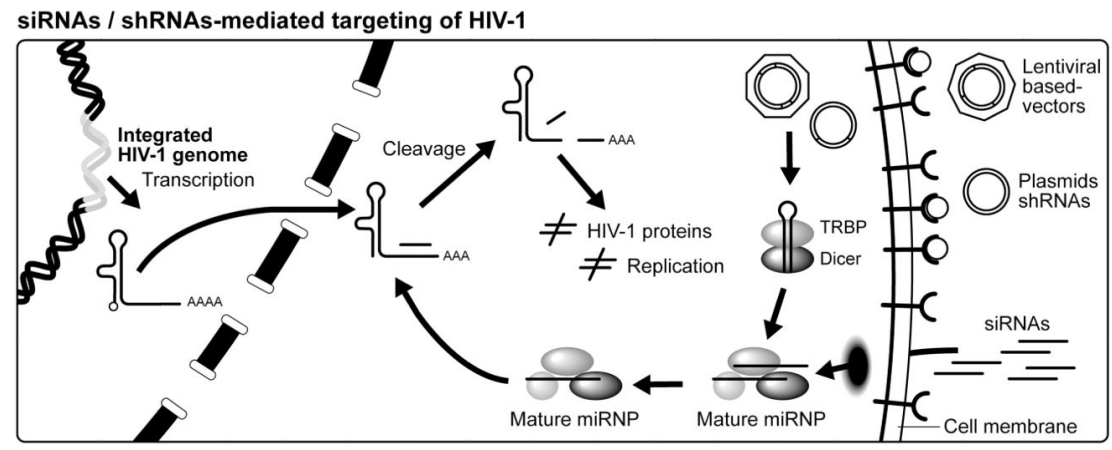

Figure 2.

siRNAs and shRNAs expressed from viral or mammalian expression vectors can mediate cleavage of HIV-1 RNAs and inhibit viral protein synthesis. 